Behavioural Sciences | Sung Joon Jang \& Byron R. Johnson

\title{
The effect of religiosity on emotional well-being among prisoners
}

Studies show that religion
enhances emotional well-being
among prisoners, but they
rarely yaddress how. Professors
Sung Joon Jang and Byron R.
Johnson at the Institute for
Studies of Religion at Baylor
University,
of religionine the on offenders in the
South African correctional
system. They test whether
religiosity is likely to lead to a
sense of meaning and purpose
in life and the development
of virtues, thereby reducing
prisoners' negative emotions.
Their findings suggest that
the concept of offender
rehabilitation should be
expanded to include how to
help offenders restore their
existential significance and

The positive effect of religion on subjective well-being is well
documented in social scientific documented in social scientific
tudies using samples of the general population, and the same effect has population, and the same efrecthas finding has practical implications because negative emotions such as anger, frustration, depression, and anxiety among prisoners may contribute to mental health problems and prison infractions including violence and suicide. Previous studies have indicated that inmates are prone to these emotions because in prisons, also called "total institutions", they not only experience the loss of liberty, access to goods and services, security sexual partners, and autonomy, but they also often struggle with feelings of shame and gult about their crimes and incarceration

Such emotions lead prisoners to face isis" where they question the meaning and purpose of develop virtuous characteristics. nature, does not help to rehabilitate offenders, and increases the risk of recidivism after release from prison. prisons have shown that religion can help combat these tendencies. Several showed that the level of prisoners' religiosity had an inverse relationship with levels of negative emotions, while others have shown that it can help prisoners overcome feelings of guilt and hopelessness.

Although most of these studies were conducted in largely Christian cultures, one study, in which half the respondents were Muslim, reported similar results. However, some studies have not found this relationship, and the few previous studies that have looked at gender are based upon predominantly male ting further research in this topic.

Taking a closer look at how religion in Sung Joon Jne of Criminology and Co-director of the Program on Prosocial Behavior the Institute for Studies of Religion at Baylor University, and Byron R. Johnson, Distinguished Professor of the Social Sciences at Baylor University and founding director of the Baylor Institute for Studies of Religion.

WHAT'S DIFFERENT

While criminologists have studied whether religion enhances emotiona well-being among prisoners, largely improve well-being improve well-being, and whether prisoners equally. Professors Jang and Johnson hypothesised that prisoners who are relglously involved will tepor those who are less or not involved in religion.

The first reason is because all religious traditions promote personal virtues, like self-control, forgiveness, accountability, and gratitude, and these help prisone overcome addictive or harmful behaviours, seek reconciliation rather than vengeance, and help them cope with the stress and negative emotions engendered by incarceration. They learn to be virtuous, and this has been labelled the "virtuous effect" of religion.

Secondly, religion can help prisoners develop a sense of meaning and "expose in life, wh what is called the goals and structure that religious belief gives individuals has also been indicated in many studies among the general. population. Religion gives people a sense of meaning and purpose that reduces negative emotions.

Jang and Johnson also hypothesised that the existential and virtuous effects of religion will be larger among female than male prisoners based on prior research that shows women benefit more from religion than men. One study showed women prisoners more likely to take up religious activities, with a significant difference in men and women becoming more religlous after a year virtuous and existential effects of religion were greater for women.

\section{HOW DID THEY DO IT?}

To test these hypo researchers analysed data from a survey conducted at four correctional centres (two male and two female) in South Africa in 2018, and used a convenience sample of 245 male and 180 female offenders. They measured negative emotions by asking offenders how often they felt angry, depressed, frustrated, and anxious dung the week prior to the survey. Religious involvement was measured tems of public activities such as religious service attendance, and practices. These included their

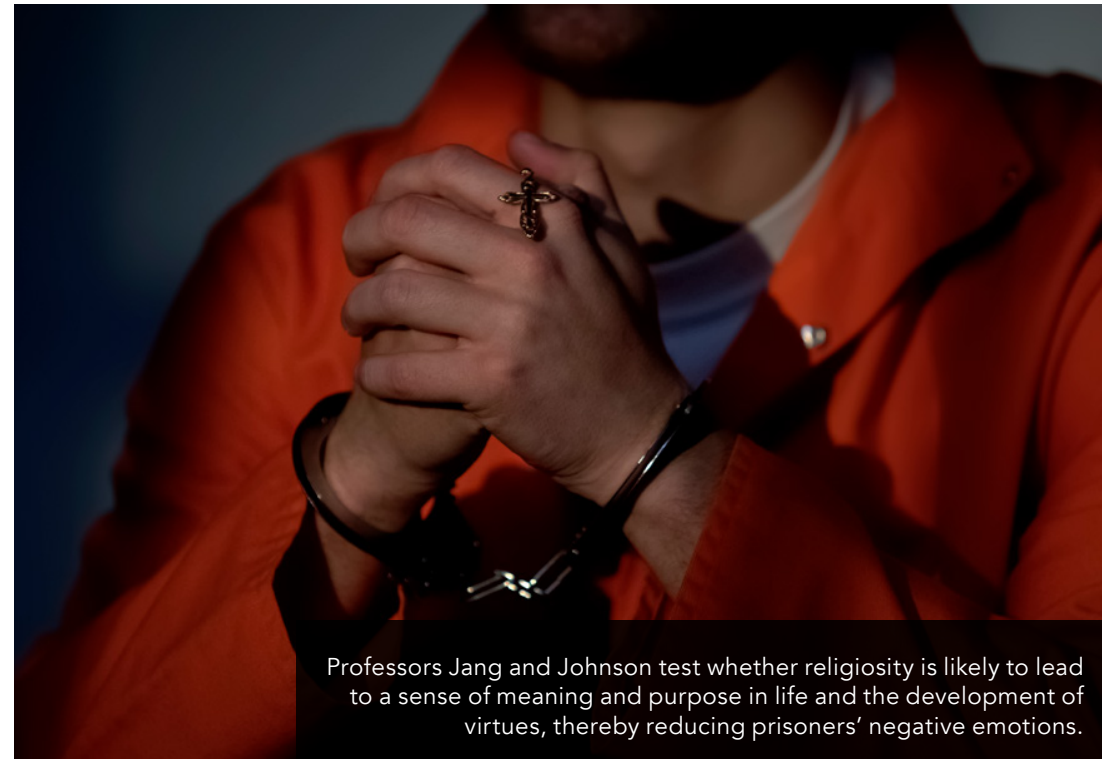

perceived closeness to God, perceived South Africa has statuary protections on of religious senvices, and reading a sacred text in private. To measure a and religious affiliations range from sense of meaning and purpose in life, Christianity to African traditional religion, they asked whether offenders knew Islam, Buddhism, Hinduism, Judaism, what makes their life meaningful and if and the Rastafarian faith/denomination, they had found a satisfying reason for although over nine out of ten of those their existence. For personal virtues, who took part in Jang and Johnson's they focused on forgiveness, gratitude, study were either Catholic or Protestant and self-control. The offender's Christian. In addition, the vast majority socio-demographic characteristics

such as nationality and marital status were also considered in order to test of offenders in correctional centres participated in religion-based spiritual care programmes that seek to rehabilitate those returning to society, which focus on

Religion"s salutary effects_existential and virtuous-were not significantly different between male and female offenders.

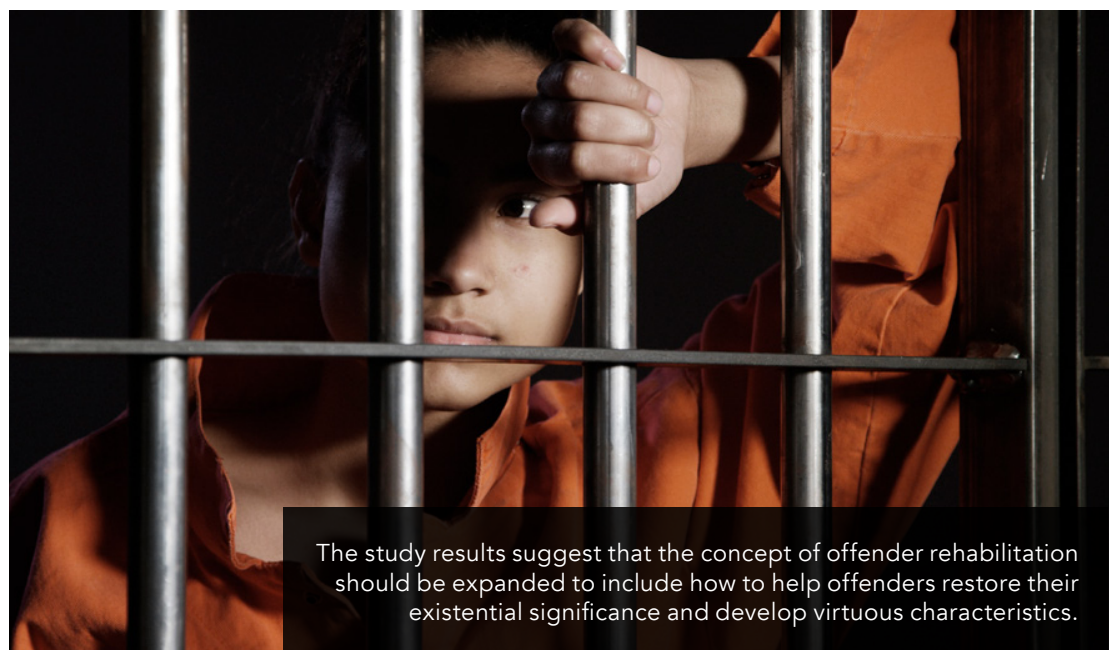




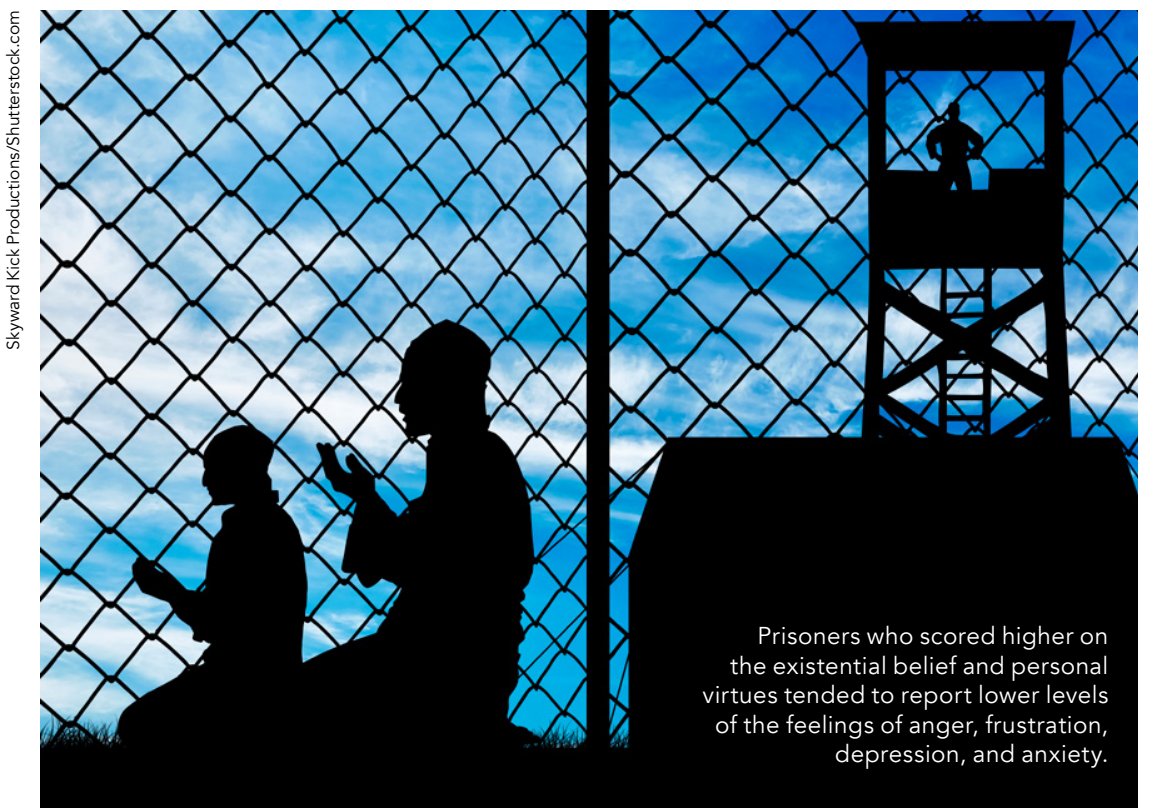

The concept of offender rehabilitation should ... include how to help offenders restore their existential significance and develop virtuous characteristics.

personal responsibility, ethical behaviour,
positive values, and respect for self and others, among other things

\section{WHAT DID THEY FIND?}

Jang and Johnson found that religious offenders reported higher levels of a sense of meaning and purpose in life, forgiveness, gratitude, and self-control than theirl ess- or non-religious peers, the existentias belief and persogh

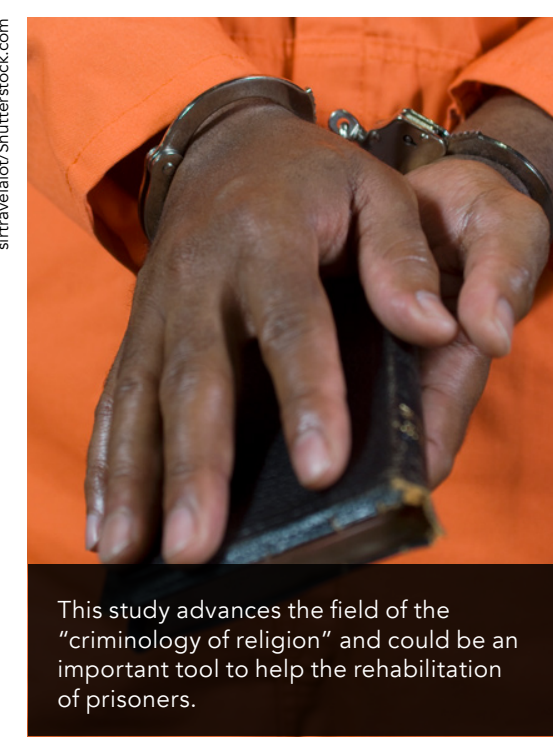

tended to report lower levels of the feelings of anger, frustration, depression, and anxiety. That is, religious offenders experienced lower levels of negative emotions partly because their religion was likely to have helped them find new meaning and purpose in life and develop virtuous characteristics, which tended to reduce negative emotions. Second, athough it was hypothesised religion than men, the researchers found that rigi, existential and virtur saus significantly different between male female offenders.

Interestingly, the researchers also came up with additional findings, one being that age was a factor. That is, everything else being equal, older offenders tended to be more forgiving and self-controlled than their younger counterparts. Another was that women tended to experience higher levels of negative emotions than men, as indicated by prior research.

\section{WHAT DOES THIS MEAN?}

In sum, Jang and Johnson's finding programmes in prison are likely to help both male and female prisoners experience as a result of the pains of imprisonment This is related to the existential purpose and meaning that religion gives to people's lives. This confirms what many studies have said before, but is significant in that this study was far more focused and in-depth, and unlike previous studies, it was conducted within a non-Western culture, and yet produced similar results. This indicates that the positive effects of religion may be cross-cultural, though the researchers admit that further research in nonWestern cultures is needed to replicate their findings.

The findings also suggest that the concept of offender rehabilitation should be expanded to include how to help offenders restore their existential significance and develop virtuous haracteristics. A change in behaviour that will lead criminals to rehabilitation and religions and faiths can facilitate this.

Professors Jang and Johnson also state that although these religious and faith-based programmes seem to have a positive effect, it's important that they remain voluntary. They believe that in addition to coerive programmes being ilegal within most prison systems, it would "compromise the intentional and voluntariness essential fo

transforming an identity".

In criminology, the traditional view of perpetrators' criminal agency is split between the utilitarian view, which states that individuals make a choice between risk and reward before committing crimes, and the deterministic view and culture. The former sees criminals as rational agents, while the latter as being moulded by external forces, but neither thinks of them in terms of being existential and moral human beings. Professors Jang and Johnson believe that this study advances the field of the "criminology of religion" and that more study is needed, as these kinds of programmes, and the could be an importanting about, could be animportant tool to help

\section{Behind the Research - \\ Prof Sung Joon Jang

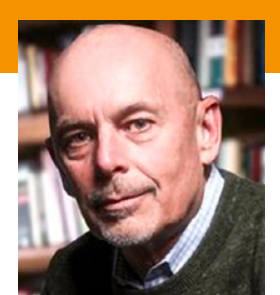 \\ Prof Byron \\ R. Johnson}

E: Sung_Joon_Jang@baylor.edu T: +1 (254) 710-1691_W: W: W: https://www.baylorisr.org/programs-research/program-on-prosocial-behavior/

Research Objectives

Professors Sung Joon Jang and Byron R. Johnson examine the role of religion in promoting emotional well-being among prisoners.

\section{Detail}

Institute for Studies of Religion

Baylor University
One Bear Place \#97236

One Bear Place

Waco, Texas
U.S.A. 76798

Bio

Sung Joon Jang is Research Professor of Criminology and Codirector of the Program on Prosocia Behavior at the Institute for Studies

\section{References}

- Jang, S. J., Johnson, B. R., Anderson, M.L., \& Booyens, K. (2019). The Effect of Religion on Emotional Well-Being Among Offenders in Correctional Centers of South Africa. Explanil 10 1080/07418825 2019.1689286 - Jang S. J Johnon B. R Hays, J, Hallet M, \& Duwe G. (2018). Existential and virtuous effects of religiosity on mental health and aggressiveness among offenders. Religions, 9(6), 182. https://doi.org/10 3390/rel9060182 - Hallett, M. Hays, J. Johnson, B. R., Jang, S. J. \& Duwe, G. (2017). The Angola prison seminary: Effects of faithbased ministry on identity transformation, desistance, and rehabilitation. New York, NY: Routledge - Jang, S. J. (2016). Existential spirituality, religiosity, and symptoms of anxiety-related disorders: A study of belief in ultimate truth and meaning in life. Journal of Psychology and Theology, 44(3), 213-229.

Lonczak, H. S., Clifasefi, S. L., Marlatt, G. A., Blume, A. W., \& Donovan, D. M. (2006). Religious coping and psychological functioning in a correctional population. Ment S. J. \& J J higon, B. R. (2005). Gender, 19 ig Jang, S. J., \& Johnson, B. R. (2005). Gender, religiosity, and reactions to strain among A

\section{Personal Response}

Given the higher proportion than other countries of South African prisoners undertaking religionhas this had on the prevels of violence or sucide in prison, and rehabilitation?

II Although spiritual care programmes focus on research makes it difficult to establish their effects on the levels of violence and suicide in prison, which a myriad of factors contribute to. Offender rehabilitation is at the core of the activities by the Department of Correctional Services. Attending spiritual care and an offender can be released on parole based on this criterion. However, the high recidivism rate suggests that not only spiritual care services but also psychological and social work services need

B. Baylor University INSTITUTE FOR STUDIES OF RELIGION 